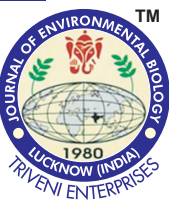

\title{
Heterotic grouping of late-maturing maize inbred lines based on combining ability and molecular marker studies
}

\begin{tabular}{lll}
\hline Paper received: 10.05 .2018 & Revised received: 30.10 .2018 & Re-revised received: 07.12 .2018 \\
\hline
\end{tabular}

\section{Authors Info \\ R.T. Maruthi ${ }^{1 *}$, R.N. Gadag ${ }^{2}$, J.S. Bhat ${ }^{3}$ and C.G. Karjagi ${ }^{4}$ \\ ${ }^{1}$ ICAR-Central Research Institute for Jute and Allied Fibres, Barrackpore-700 120, India \\ ${ }^{2}$ ICAR- Indian Agricultural Research Institute, New Delhi-110 012, India \\ ${ }^{3}$ Regional Research Centre, ICAR-Indian Agricultural Research Institute, Dharwad-580 005, India ${ }^{4}$ ICAR-Indian Institute of Maize Research, Pusa Campus, New Delhi-110 012, India \\ *Corresponding Author Email : maru7806@gmail.com}

\section{Edited by \\ Dr. Umesh Hudedamani}

Reviewed by Dr. Alireza Seidavi Dr. R.B. Raizada

\section{Abstract}

Aim : To examine concurrence between yield based and SSR marker based heterotic grouping of latematuring maize inbred lines.

Methodology : A total of $45 \mathrm{~F}_{1}$ crosses derived from $10 \times 10$ diallel mating scheme were evaluated along with their parents and hybrid checks across two locations (New Delhi and Dharawada).To group the inbred lines at molecular level, 35 polymorphic SSR primers were used for PCR amplification of repeat sequences from the genomic DNA of each inbred isolated by CTAB method. Cluster analysis was carried out by using NTSYS-pc-2.02.

Results : Analysis of variance revealed significant $(P<0.01)$ variation among the parents and their hybrids across two locations for all the traits. The yield SCA classified 10 latematuring maize inbred lines into three heterotic groups. Similarly, molecular genetic diversity analysis also Heterotic grouping of late-maturing maize inbred lines

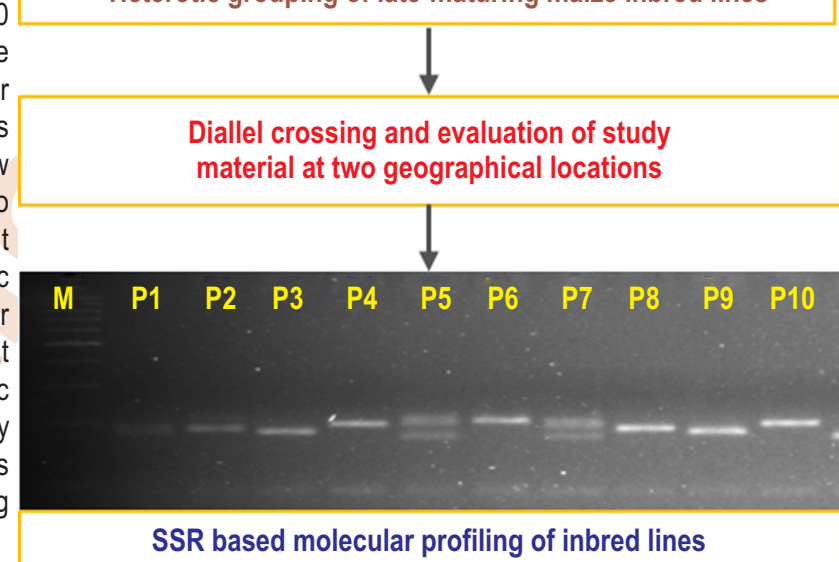
(he inbred lines into three major clusters. However, correlations between SCA effects and genetic distance were low ( $r=0.161)$ for grain yield.

Interpretation : Heterosis prediction with the help of molecular markers alone was not found effective. Further, field-testing can be complimented with molecular markers for the elimination of inferior crosses.

Key words: Combining ability, Dendrogram, Heterotic groups, Maize, Simple sequence repeats

How to cite : Maruthi, R.T., R.N. Gadag, J.S. Bhat and C.G. Karjagi: Heterotic grouping of late-maturing maize inbred lines based on combining ability and molecular marker studies. J. Environ. Biol., 40, 705-710 (2019). 


\section{Introduction}

Genetic diversity is a prerequisite for the success of any crop improvement programme. In maize, introduction of exotic germplasm lines were found promising in enhancing the genetic variation and also to improve the productivity of local maize varieties. However, for the efficient use of introduced germplasm, preliminary information on genetic diversity and heterotic pattern between exotic and local maize germplasm is essential (Fan et al., 2008). In heterosis breeding and population improvement programmes, breeders have to evaluate thousands of crosses in replicated field trials to eliminate inferior crosses. The success of such breeding effort lies in the efficiency of procedure employed to identify parenta lines, which can be crossed to develop outstanding single cross hybrid. Heterotic grouping of inbred lines is one such strategy, where probability of obtaining superior heterotic hybrids increases when inbred lines belonging to different heterotic groups are crossed (Reif et al., 2003; Singode et al., 2017).

Heterotic group is defined as "a group of related or unrelated genotypes from the same or different populations, which display similar combining ability and heterotic response when crossed with genotypes from other genetically distinct germplasm groups". There are several methods such as quantitative genetics analysis, pedigree analysis and molecular marker analysis for classifying the genotypes into different heterotic groups. Combining ability analysis using diallel mating design developed by Griffing (1956) is one of the widely used biometrical techniques. This method has been employed by several researchers to define heterotic patterns in maize (Laude and Salazar, 2008; Bidhendi et al., 2011; Laude and Carena 2015; Amegbor et al., 2017) and other crops (Torres and Geraldi, 2007; Farshadfar et al., 2013) and animals (Seidavi, 2010; Balaguer, 2014; Roy et al., 2018).

Combining ability studies alone may not be efficient to classify inbred lines into distinct heterotic groups. It can be better complimented with the use of molecular markers that allow direct comparison of genetic similarity between inbred lines at DNA level (Reif et al., 2003). Among various molecular tools, simple sequence repeats (SSRs) were widely used in maize for heterotic grouping of inbred lines (Pabendon et al., 2009; Akinwale et al., 2014; Rajendran et al., 2014). In the present study, an effort was made to understand the heterotic pattern of available superior latematuring inbred lines and to test the concurrence between yield based and SSR marker based classification of the inbred lines.

\section{Materials and Methods}

Plant material and field evaluation: The material selected for the present study consisted of ten late-maturing maize inbred lines (Table 1) maintained in the Maize Genetics Unit, Indian Agricultural Research Institute, New Delhi. Hybridization in half diallel fashion was done among the inbred lines according to Griffing's diallel method II (Griffing, 1956) during rabi season at
Winter Nursery Centre, Indian Institute of Maize Research, Hyderabad. Forty five F1 hybrids, parents and two checks (PMH1, PMH-3) were evaluated under randomized complete blocks design with three replications in kharif season at two test locations viz., New Delhi and Dharawada.

Each genotype was grown in a single-row plot of $5 \mathrm{~m}$ long, spaced $75 \mathrm{~cm}$ apart. Further, plant to plant spacing of $25 \mathrm{~cm}$ within each row was maintained. Proper package of practices was followed to raise the good crop at both the test locations. Data on 11 morphological traits were recorded on five randomly selected plants in each row. The grain yield data was subjected to $F$ test in order to test the homogeneity of variance (Gomez and Gomez, 1984). Analyses of variance and combining ability analysis was performed using Windost software package (WINDOSTAT ver. 9.1) following method II of Griffing's fixed effect model. The inbred lines were classified into different heterotic groups based on specific combining ability (SCA) effects of grain yield per plant. The SCA data was used as dissimilarity coefficients for cluster analysis in unweighted pair group method with arithmetic averages (UPGMA) method.

Analyses of molecular diversity: Leaf sample from 21-day-old plants were collected and DNA was isolated using modified CTAB procedure (Saghai-Maroof et al., 1984). Primers with banding pattern difficult to score and monomorphic were excluded. Final set of 35 SSR primers (Table 2) were selected out of 50 SSR primers for further analysis. SSR alleles were scored sequentially from the largest to the smallest size band based on their position relative to the ladder. Genetic similarity (GS) matrix was generated using Jaccard's coefficient. Similarity matrix was analysed using NTSYS-pc-2.02 to draw cluster diagram.

\section{Results and Discussion}

Analysis of variance revealed highly significant $(P<0.01)$ differences among the parents and hybrids for grain yield across environments (Table 3), which indicate the presence of ample variation in the genotypes studied and it also infers that inbreds can be utilized for the development of location specific varieties. Interaction of environmentxgenotype was highly significant $(P<0.01)$ indicating that yield of genotypes were different in different environments. GCA and SCA variances were highly significant for most of the traits indicating the importance of both additive and non-additive gene actions in the inheritance of these traits (Choukan and Mosavat, 2006; Zare et al., 2010; BaduApraku etal., 2015; Amegbor et al., 2017).

Highly significant differences were observed for GCA interaction variance in the traits like ear length, ear girth, plant height and hundred seed weight. Similarly, for SCA interaction variance almost all the traits exhibited highly significant differences. Significance of interaction variance for majority of traits indicate that variations in the combining abilities of inbred lines and yield performance of single-crosses evaluated across environment was not consistent. Hence, this suggested the need 
Table 1: Description of 10 maize inbred lines and two checks used in the study

\begin{tabular}{lllll}
\hline Abbreviation & Inbred line & $\begin{array}{l}\text { Preliminary } \\
\text { group }\end{array}$ & $\begin{array}{l}\text { Days to } \\
\mathbf{5 0 \%} \text { silk }\end{array}$ & Other characteristics \\
\hline P1 & IPA26368 & 1 & 63 & Yellow-orange, flint \\
P2 & 2 & 59 & Orange, flint \\
P3 & IPA26011 & 3 & 61 & Orange, flint \\
P4 & IPA26023 & 2 & 61 & Yellow-orange, flint \\
P5 & IPA26038 & 2 & 56 & Orange, flint \\
P6 & IPA26051 & 2 & 57 & Yellow-orange, flint \\
P7 & IPA26055 & 2 & 58 & Orange, flint \\
P8 & IPA26063 & 2 & 56 & Yellow, flint \\
P9 & IPA26076 & 2 & 59 & Yellow, flint \\
P10 & IPA26077 & 3 & 59 & Yellow-orange, flint \\
Check 1 & IPA26085 & - & 60 & Yellow-orange, flint \\
Check 2 & PMH 1 & - & 60 & Orange, flint \\
\hline
\end{tabular}

to identify and select specific inbred lines and single-crosses for specific environments (Akinwale et al., 2014). The inbred lines with significant $(P<0.05)$ positive GCA for grain yield were $P_{5}$ $(0.42)$ and $P_{6}(0.19)$ (Table 4). These two inbred lines were identified as best general combiners for majority of traits. Since GCA effect is controlled by additive genes inclusion of inbreds with high GCA effect in breeding program can accelerate yield improvement process (Dar et al., 2016).

A total of seventeen crosses revealed highly significant positive SCA effect for grain yield across two locations, and top three crosses with highest SCA value were $P_{9} x P_{10}$ (1.95), $P_{4} x P_{5}$ (1.44) and $P_{3} x P_{6}$ (1.43). Since these hybrids produced high grain yield across two test environments, they can be readily evaluated under coordinated yield trials as single cross hybrids. A significant positive SCA for grain yield of some of the hybrids were a product of certain inbred lines observed with low and negative GCA estimates. Such positive performance of high $\mathrm{x}$ low combination may be due to the interaction between dominant favourable alleles from good general combiners and unfavourable recessive alleles from poor combiners (Owusu et al., 2017). Three heterotic groups were formed based on cluster analysis using UPGMA on SCA effects of yield data (Fig. 1a). Group A consisted of lines P1 P6, P7, P8 and P9. Inbreds P5 and P10 fall into group B. Group C. contained P2, P3 and P4. According to the assumption, SCA of two lines from different heterotic groups are greater than those from the same group (Amegbor et al., 2017). The heterotic group with high performing inbred lines is best suited for the

Table 2: Genomic location, SSR locus, repeat type and number of alleles produced by each of the 35 SSR locus

\begin{tabular}{llllllll}
\hline Marker & Bin no. & Repeat type & No. of allels & Marker & Bin no. & Repeat type & No. of allels \\
\hline umc2226 & 1.02 & (TGG)6 & 4 & umc2319 & 6.05 & (GAGGAG)5 & 2 \\
bnlg439 & 1.03 & Unspecified & 3 & umc2165 & 6.07 & (TTC)12 & 2 \\
umc1452 & 1.04 & (GCC)4 & 3 & umc2324 & 6.08 & (CAC)4 & 2 \\
umc2083 & 1.06 & (CGG)7 & 2 & umc2364 & 7.01 & (GGA)7 & 2 \\
umc1446 & 1.08 & (TAA)7 & 2 & umc1831 & 7.02 & (AG)8 & 2 \\
umc1704 & 2.09 & Unspecified & 2 & umc2330 & 7.03 & (GAGA)5 & 2 \\
umc2220 & 2.07 & Unspecified & 2 & umc2332 & 7.04 & (CTC)5 & 3 \\
umc2262 & 3.04 & (CATCT)5 & 3 & umc2334 & 7.06 & (GGA)4 & 2 \\
umc1102 & 3.05 & GGAT & 3 & phi125 & 8.03 & AG & 2 \\
umc1690 & 3.07 & (GCA)4 & 2 & bnlg240 & 8.06 & Unspecified & 2 \\
umc1757 & 4.01 & (TCC)7 & 2 & phi028 & 9.01 & GAA & 3 \\
phi021 & 4.03 & AG & 3 & umc1714 & $9.07 / 08$ & (GGC)4 & 2 \\
umc2061 & 4.05 & (CTG)8 & 2 & umc2130 & 9.02 & Unspecified & 2 \\
umc1869 & 4.06 & (GGT)6 & 2 & umc1318 & 10.02 & (GTC)5 & 2 \\
umc2373 & 5.04 & (GCT)4 & 3 & umc2017 & 10.03 & (CAA)4 & 2 \\
umc1153 & 5.09 & (TCA)4 & 2 & umc2043 & 10.05 & (TCC)4 & 2 \\
umc1723 & 6.02 & (CTT)6 & 2 & umc2021 & 10.07 & (TGG)4 & 3 \\
bnlg1014 & 6.04 & Unspecified & 2 & & & & \\
\hline
\end{tabular}


Table 3: Mean squares from the combined ANOVA of grain yield and other traits of late-maturing inbred lines evaluated across research environments

\begin{tabular}{|c|c|c|c|c|c|c|c|c|c|c|c|c|}
\hline \multirow{2}{*}{ Source } & \multirow{2}{*}{ DF } & \multicolumn{10}{|c|}{ Mean square } & \multirow[b]{2}{*}{ GYPPT } \\
\hline & & DFA & DFS & ASI & $\mathrm{PH}$ & EH & EL & EG & NGPR & NRW & HSW & \\
\hline Env. $(E)$ & 1 & 2965.46 ** & $2644.01^{* *}$ & $9.70^{* *}$ & $61621.14^{\star *}$ & $25432.44^{\star *}$ & $98.72^{\star \star *}$ & $2.61^{* *}$ & $56.35^{\star *}$ & 0.06 & 2.94 & $6.79^{\star \star}$ \\
\hline Genotypes (G) & 54 & $8.83^{\star *}$ & $9.49^{\star \star}$ & $0.81^{* *}$ & $822.68^{* *}$ & $870.88^{* *}$ & $11.89^{* *}$ & $1.06^{* *}$ & $88.47^{\star *}$ & $7.14^{* *}$ & $30.95^{\star *}$ & $13.10^{\star *}$ \\
\hline $\mathrm{G}^{*} \mathrm{E}$ & 54 & $16.78^{\star *}$ & $14.09^{* *}$ & $1.10^{* *}$ & $696.06^{* *}$ & $481.53^{\star *}$ & $4.20^{\star *}$ & $0.28^{* *}$ & $22.62^{\star *}$ & $1.39^{* *}$ & $17.40^{* *}$ & $1.46^{\star \star}$ \\
\hline GCA & 9 & 1.87 & $3.04^{* *}$ & $0.42^{* *}$ & $249.95^{\star *}$ & $77.07^{\star *}$ & $4.36^{\star *}$ & $0.24^{* *}$ & $19.74^{* *}$ & $2.50^{* *}$ & $12.09^{* *}$ & $0.91^{* *}$ \\
\hline SCA & 45 & $3.16^{*}$ & $3.19^{\star *}$ & $0.24^{*}$ & $279.08^{* *}$ & $332.94^{* *}$ & $3.89^{* *}$ & $0.38^{* *}$ & $31.44^{* *}$ & $2.36^{\star *}$ & $9.97^{* *}$ & $5.06^{\star *}$ \\
\hline $\mathrm{GCA}^{*} \mathrm{E}$ & 9 & 1.93 & 2.01 & 0.22 & $106.72^{* *}$ & $58.65^{*}$ & $1.81^{* *}$ & $0.13^{* *}$ & $3.89^{*}$ & $0.55^{\star}$ & $5.05^{\star *}$ & $0.42^{*}$ \\
\hline$S C A^{*} E$ & 45 & $6.33^{* *}$ & $5.24^{* *}$ & $0.40^{* *}$ & $257.08^{* *}$ & $180.88^{* *}$ & $1.32^{* *}$ & $0.09^{* *}$ & $8.27^{\star *}$ & $0.45^{\star *}$ & $5.95^{\star *}$ & $0.50^{* \star}$ \\
\hline Error & 216 & 1.33 & 1.21 & 0.15 & 35.26 & 29.74 & 0.56 & 0.02 & 1.63 & 0.27 & 1.23 & 0.21 \\
\hline
\end{tabular}

$D F$ : degree of freedom, DFA: days to $50 \%$ anthesis, DFS: days to $50 \%$ silking, $A S I$ : anthesis-silking interval, $P H$ : plant height (cm), EH: ear height (cm), $E L$ : ear length (cm), EG : ear girth (cm), NGPR: no. of grains per row, NRW: no. of grain rows per ear, HSW : 100 seed weight (gm), GYPPT: seed yield per plot $\left(\mathrm{kg} \mathrm{plot}^{-1}\right) .{ }^{*}{ }^{* *}$ Significant levels at 0.05 , and 0.01 probability levels

Table 4: Estimates of GCA and SCA effects among 10 late-maturing maize inbred lines for grain yield $\left(\mathrm{kg} \mathrm{plot}^{-1}\right)$

\begin{tabular}{|c|c|c|c|c|c|c|c|c|c|c|}
\hline \multirow{2}{*}{ Inbreds } & \multirow{2}{*}{ GCA } & \multicolumn{9}{|c|}{ SCA } \\
\hline & & $P_{1}$ & $\mathbf{P}_{2}$ & $P_{3}$ & $P_{4}$ & $P_{5}$ & $P_{6}$ & $\mathbf{P}_{7}$ & $\mathbf{P}_{8}$ & $P_{9}$ \\
\hline P1 & $-0.25^{\star *}$ & & & & & & & & & \\
\hline P2 & -0.1 & $1.24^{* *}$ & & & & & & & & \\
\hline P3 & -0.09 & $0.65^{*}$ & -0.09 & & & & & & & \\
\hline P4 & 0.06 & $0.74^{*}$ & $0.69^{*}$ & -0.42 & & & & & & \\
\hline P5 & $0.42^{* *}$ & 0.41 & $0.95^{* *}$ & $1.23^{* *}$ & $1.44^{* *}$ & & & & & \\
\hline P6 & $0.19^{*}$ & $-0.84^{* *}$ & $1.24^{* *}$ & $1.43^{* *}$ & 0.49 & $0.92^{* *}$ & & & & \\
\hline P7 & -0.17 & 0.54 & 0.46 & $0.97^{* *}$ & 0.46 & $1.33^{* *}$ & 0.39 & & & \\
\hline P8 & -0.09 & $0.84^{* *}$ & $0.80^{* *}$ & $0.71^{*}$ & $1.09^{* *}$ & $0.61^{*}$ & 0.51 & 0.26 & & \\
\hline P9 & 0.07 & $0.74^{*}$ & $1.20^{* *}$ & $1.21^{* *}$ & 0.59 & 0.22 & 0.28 & $-0.65^{*}$ & 0.25 & \\
\hline P10 & -0.05 & $1.04^{* \star}$ & -0.03 & $0.61^{*}$ & $0.87^{\star *}$ & -0.44 & $0.67^{*}$ & $0.60^{*}$ & 0.28 & $1.95^{\star \star}$ \\
\hline
\end{tabular}

*, ** Significant levels at 0.05 , and 0.01 probability levels

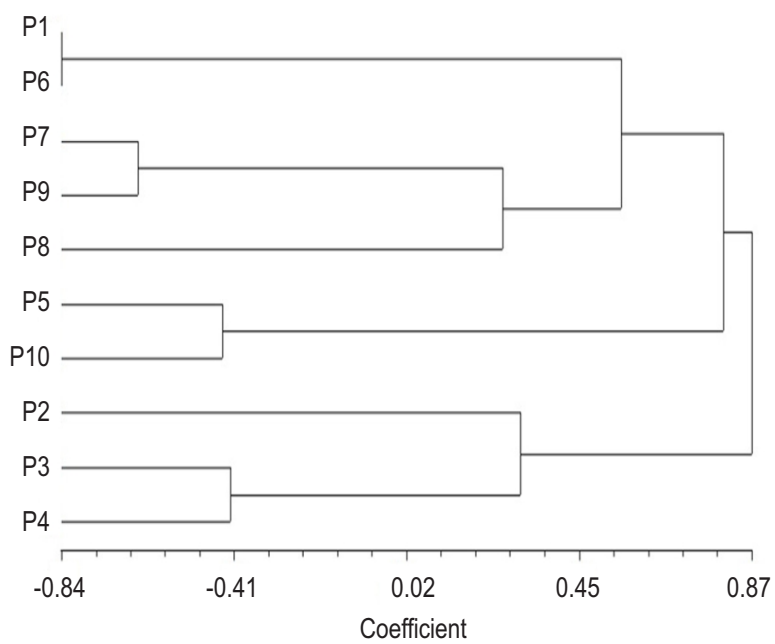

A

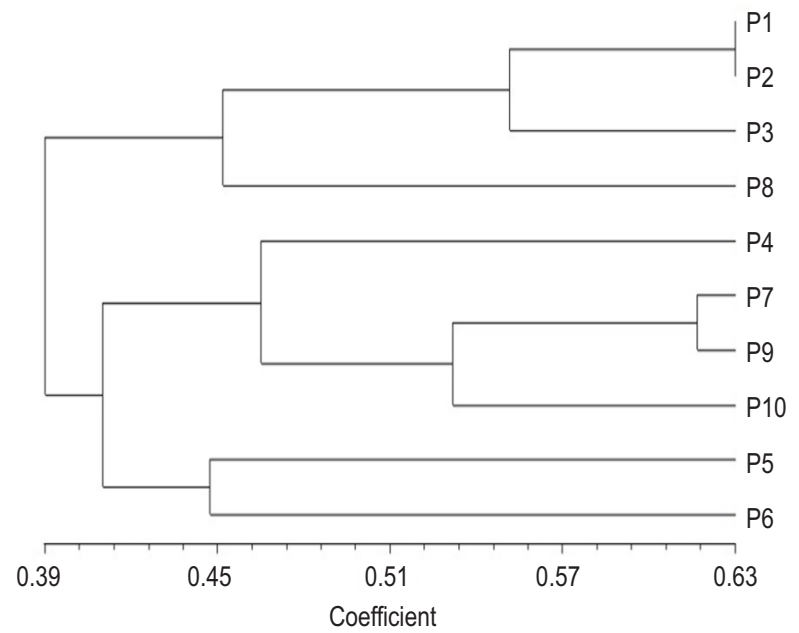

B

Fig. 1: Association among 10 late-maturing maize inbred lines revealed by UPGMA cluster analysis generated by (a)SCA effect and (b) 35 SSR markers. 
development of synthetic and composite varieties. Further, manifestation of high degree of heterosis in crosses between heterotic groups denotes genetic diversity between groups (BaduApraku et al., 2015). Probability of obtaining superior hybrids increases when parental lines are selected from diverse groups.

35 SSR primers produced 83 alleles among the ten latematuring inbred lines. The average number of alleles amplified per locus was 2.3 ranging from two to four (Table 2). In a similar study, Fan et al. (2004) reported a range of 2-5 alleles per locus and a mean of 2.84 while assessing the genetic diversity of 10 QPM inbred lines with 37 SSR primers. The lowest genetic similarity of 0.308 was observed between $P_{1}$ vs $P_{5}$ whereas the highest was found between $P_{1} v s P_{2}$ with 0.625 . Based on the UPGMA cluster analysis, 10 late-maturing inbred lines were grouped into three major clusters (Fig. 1b). Cluster I harbored lines P1, P2, P3 and P8. Inbreds P4, P7, P9 and P10 fall in cluster II, while Cluster III contained the lines P5 and P6. Among the molecular markers, use of SSR markers for heterotic grouping in maize has proven valuable (Akinwale et al., 2014; Rajendran et al., 2014; Sharma et al., 2017).

The correlation coefficient between genetic distance estimates of ten late-maturing inbred lines and their corresponding grain yield SCA effect $(r=0.161)$ was positive and insignificant. It depicts existence of poor correlation between heterosis and genetic distance. There may be several factors responsible for poor correlation like random distribution of marker, use of few markers for the study, unequal genome coverage and lack of linkage between genes controlling yield related traits (Kwon et al., 2002; Akinwale et al., 2014; Rajendran et al., 2014). From the above results, it can be concluded that with the help of molecular markers alone it is not possible to accurately predict the hybrid performance.

The present study revealed highly significant variations among the study material for all the yield-contributing traits. Based on combining ability results, the parents $\mathrm{P}_{5}$ (IPA26051) and $P_{6}$ (IPA26055) were identified as donors for grain yield improvement in hybrid breeding. Based on the grain yield SCA, the cross combination $\mathrm{P}_{9} \times \mathrm{P}_{10}$ (IPA26077 $\mathrm{x}$ IPA26085), $\mathrm{P}_{4} \times \mathrm{P}_{5}$ (IPA26038 x IPA26051) and $\mathrm{P}_{3} \times \mathrm{P}_{6}$ (IPA26023 x IPA26055) have been identified as promising $F_{1}$ hybrids for grain yield, hence these hybrids have been recommended for heterosis breeding. Our findings further confirmed that heterosis prediction with the help of set of molecular markers alone was not found effective.

\section{References}

Akinwale, R.O., B. Badu-Apraku, M.A.B. Fakorede and I. Vroh-Bi: Heterotic grouping of tropical early-maturing maize inbred lines based on combining ability in Striga-infested and Striga-free environments and the use of SSR markers for genotyping. Field Crops Res.,156, 48-62 (2014).

Amegbor, I.K., B. Badu-Apraku and B. Annor: Combining ability and heterotic patterns of extra-early maturing white maize inbreds with genes from Zea diploperennis under multiple environments.
Euphytica, 213, 42 (2017).

Badu-Apraku, B., B. Annor, M. Oyekunle, R.O. Akinwale, M.A.B. Fakorede, A.O. Talabi, I.C. Akaogu, G. Melaku and Y. Fasanmade: Grouping of early-maturing quality protein maize inbreds based on SNP markers and combining ability under multiple environments. Field Crops Res., 183, 169-183 (2015).

Bidhendi, M.Z., R. Choukan, F. Darvish, K. Mostafavi and E.M. Hervan: Determination of combining abilities and heterotic patterns of fourteen medium to late maturing Iranian maize inbred lines using diallel mating design. Afr. J. Biotechnol.,10, 16854-16865 (2011).

Choukan, R. and S.A. Mosavat: Mode of gene action of different traits in maize tester lines using diallel crosses. Seed and Plant, 4, 547556 (2006).

Dar, Z.A., S.A. Wani and M.A. Wani: Heterosis and combining ability analysis for seed yield and its attributes in Brassica rapas sp. Brown sarson. J. Oilseed Brass., 2, 21-28 (2016).

Fan, X.M., H.M. Chen, J. Tan, C.X. Xu, Y.M. Zhang, Y.X. Huang and M.S. Kang: A new maize heterotic pattern between temperate and tropical germplasms. Agron. J., 100, 917-923 (2008).

Fan, X.M., J. Tan, J.Y. Yang and H.M. Chen: Combining ability and heterotic grouping of ten temperate, subtropical and tropical quality protein maize inbreds. Maydica, 49, 267-272 (2004).

Farshadfar, E., F. Rafiee and H. Hasheminasab: Evaluation of genetic parameters of agronomic and morpho-physiological indicators of drought tolerance in bread wheat (Triticum aestivum L.) using diallel mating design. Aust. J. Crop Sci., 7, 268-275(2013).

Gomez, K.A. and A.A. Gomez: Statistical procedures for agricultural research. A Wiley-Interscience Publication, John Wiley and Sons, New York (1984).

Griffing, B.: Concept of general and specific combining ability in relation to diallel crossing systems. Aust. J. Biol. Sci., 9, 463-493 (1956).

Kwon, S.J., S.N. Ahn, E.G. Jeong, H.G. Hwang, H.C. Choi and H.P. Moon: Relationship between genetic divergence and hybrid performance in Japonica rice grown in a cold water irrigated field. Euphytica, 128, 389-396 (2002).

Laude, T.P. and A.M. Salazar: Combining ability and heterotic relationships in yellow quality protein maize varities. Philipp. J. Crop Sci., 33, 25-36 (2008).

Laude, T.P. and M.J. Carena: Genetic diversity and heterotic grouping of tropical and temperate maize populations adapted to the northern U.S. corn belt. Euphytica, 204,661-677 (2015).

Owusu, G.A., D. Nyadanu, K. Obeng-Antwi, R.A. Amoah, F.C. Danso and S. Amissah: Estimating gene action, combining ability and heterosis for grain yield and agronomic traits in extra-early maturing yellow maize single-crosses under three agro-ecologies of Ghana. Euphytica, 213, (2017). 10.1007/s10681-017-2081-3.

Pabendon, M. B., M.J. Mejaya, J. Koswara and H. Aswidinnoor: SSRbased genetic diversities among maize inbred lines and their relationships with $F_{1}$ phenotypic data of MR4 and MR14 testcrosses. Indones. J. Agric., 2, 41-48 (2009).

Rajendran, A., A. Muthiah, J. Joel, P. Shanmugasundaram and D. Raju: Heterotic grouping and patterning of quality protein maize inbreds based on genetic and molecular marker studies. Turk. J. Biol., 38, 10-20 (2014).

Reif, J.C., A.E. Melchinger, X.C. Xia, M.L. Warburton, D.A. Hoisington, S.K. Vasal, G. Srinivasan, M. Bohn and M. Frisch: Genetic distance based on simple sequence repeats and heterosis in tropical maize populations. Crop Sci., 43, 1275-1282 (2003).

Roy, M., P.K. Senapati, M.C. Pakhira, U. Sarkar and S. Datta: Studies of inheritance of resistance to Haemonchus contortus through diallel mating in Garole sheep. J. Entomol. Zool. Stud., 6, 569573 (2018). 
Saghai-Maroof, M. A., K.M. Soliman, R.A. Jorgensen and R.W. Allard: Ribosomal DNA spacer length polymorphisms in barley: Mendelian inheritance, chromosomal location and population dynamics. Proc. Natl. Acad. Sci.USA., 81, 8014-8018 (1984).

Seidavi, A.R.: Estimation of genetics parameters and selection effect on genetic and phenotype trends in silkworm commercial pure lines. Asian J. Anim. Vet. Adv., 5, 1-12 (2010).

Sharma, T., A. Kumar, S.C. Dwivedi and R.P. Vyas: Molecular characterization and genetic diversity analysis of selected maize inbreds using SSR markers. J. Env. Biol., 39, 228-236 (2017).
Singode, A., A. Manivannan, B. Ahmad, E. Srivastava and V. Mahajan: Heterotic grouping in early maturing Indian maize lines. Int. J. Agric. Res. Innov. Technol., 6, 57-62 (2017).

Torres, E.A. and I.O. Geraldi: Partial diallel analysis of agronomic characters in rice (Oryza sativa L.). Genet. Mol. Biol., 30, 605-613 (2007).

Zare, M., R. Chouckan, M.R. Bihamta and E.M. Hervan: Estimation of genetic parameters and general and specific combining abilities in maize using a diallel design. Iran. J. Crop Sci., 47, 318-332 (2010). 